\title{
Should less-invasive aortic valve replacement be avoided in patients with pulmonary dysfunction?
}

Turki B. Albacker, MD, MSc, ${ }^{\text {a,b }}$ Eugene H. Blackstone, MD, ${ }^{\text {a,c }}$ Sarah J. Williams, MS, ${ }^{c}$

A. Marc Gillinov, MD, ${ }^{a, b}$ Jose L. Navia, MD,${ }^{\mathrm{a}, \mathrm{b}}$ Eric E. Roselli, MD, ${ }^{\mathrm{a}, \mathrm{b}}$ Suresh Keshavamurthy, MBBS, MS, ${ }^{\mathrm{a}}$ Gösta B. Pettersson, MD, PhD, ${ }^{\mathrm{a}, \mathrm{b}}$ Tomislav Mihaljevic, MD, ${ }^{\mathrm{a}, \mathrm{b}}$ Douglas R. Johnston, MD, ${ }^{\mathrm{a}, \mathrm{b}}$ Joseph F. Sabik III, MD, ${ }^{\mathrm{a}, \mathrm{b}}$ Bruce W. Lytle, MD, ${ }^{\mathrm{a}, \mathrm{b}}$ and Lars G. Svensson, MD, PhD ${ }^{\mathrm{a}, \mathrm{b}}$

Objective: In patients with pulmonary dysfunction, it is unclear whether a less-invasive approach for aortic valve replacement is well tolerated or even beneficial. We investigated whether a partial upper J-incision for aortic valve replacement leads to more favorable outcomes than a full sternotomy in patients with chronic lung disease by using forced expiratory volume in 1 second as a surrogate.

Methods: From January 1995 to July 2010, 6931 patients underwent primary isolated aortic valve replacement; 655 had forced expiratory volume in 1 second measured and expressed as percent of predicted (FEV1\%;368 via J-incision, 287 via full sternotomy). Postoperative outcomes were compared among 223 propensity-matched pairs.

Results: Patients diagnosed with chronic lung disease had longer median intensive care unit (41 vs 27 hours, $P=.001)$ and postoperative (7.1 vs 6.1 days, $P<.0001)$ lengths of stay than those without chronic lung disease. At normal values of FEV1\%, little difference was observed in either of these times for J-incision versus full sternotomy; however, at progressively lower FEV1\%, these times lengthened, with increasing benefit for J-incision. Among propensity-matched patients, other postoperative complications were similar. Early survival ( $93 \%$ vs $89 \%$ at 1 year, $P=.07$ ) was possibly higher in matched patients with J-incision, but late survival was similar $(P=.9)$. Patients with FEV1\% less than 50 who underwent J-incision had the greatest survival advantage, which persisted for 5 years.

Conclusions: In patients with preoperative respiratory dysfunction, a less-invasive partial upper J-incision for aortic valve replacement can lead to more favorable outcomes than a full sternotomy, including shorter intensive care unit and postoperative lengths of stay and better early survival, which are amplified with decreasing pulmonary function. (J Thorac Cardiovasc Surg 2014;147:355-61)

\footnotetext{
From the Department of Thoracic and Cardiovascular Surgery ${ }^{\mathrm{a}}$ and Aorta Center, ${ }^{\mathrm{b}}$ Heart and Vascular Institute, Cleveland Clinic, Cleveland, Ohio; and Department of Quantitative Health Sciences, ${ }^{\mathrm{c}}$ Research Institute, Cleveland Clinic, Cleveland, Ohio.

Funding: This study was supported in part by the Kenneth Gee and Paula Shaw, $\mathrm{PhD}$, Chair in Heart Research (Dr Blackstone); the Peter and Elizabeth C. Tower and Family Endowed Chair in Cardiothoracic Research, James and Sharon Kennedy, the Slosburg Family Charitable Trust, Stephen and Saundra Spencer, and Martin Nielsen (Dr Pettersson); the Judith Dion Pyle Endowed Chair in Heart Valve Research (Dr Gillinov); the Donna and Ken Lewis Chair in Cardiothoracic Surgery and Peter Boyle Research Fund (Dr Mihaljevic); and the Sheikh Hamdan bin Rashid Al Maktoum Distinguished Chair in Thoracic and Cardiovascular Surgery (Dr Sabik). Disclosures: Dr Gillinov is a consultant for Edwards Lifesciences and Onyx Lifesciences and receives research support from St Jude Medical and Medtronic. Dr Johnston is a consultant and speaker for Baxter Healthcare and St Jude Medical. Dr Roselli is a consultant for Medtronic and Edwards Lifesciences and a teacher and speaker for Cook Medical and Terumo Medical. Dr Sabik is a consultant for Medtronic and ValveXchange and receives lecture fees from Edwards Lifesciences. Dr Svensson holds stock in Cardiosolutions and ValveXchange and receives royalties from Post-Thorax. All other authors have nothing to disclose with regard to commercial support.

Received for publication March 7, 2012; revisions received Oct 30, 2012; accepted for publication Dec 5, 2012; available ahead of print Jan 18, 2013.

Address for reprints: Lars G. Svensson, MD, PhD, Aorta Center, Department of Thoracic and Cardiovascular Surgery, Cleveland Clinic, 9500 Euclid Ave/Desk J4-1, Cleveland, OH 44195 (E-mail: svenssl@ ccf.org).

$0022-5223 / \$ 36.00$

Copyright (c) 2014 by The American Association for Thoracic Surgery

http://dx.doi.org/10.1016/j.jtcvs.2012.12.014
}

Supplemental material is available online.

Patients with severe respiratory dysfunction and chronic lung disease (CLD) are being seen more frequently, particularly for various types of transcatheter aortic valve replacement (AVR). ${ }^{1}$ Whether these patients would tolerate or even benefit from a surgical AVR via a less-invasive J-incision rather than a full sternotomy is unknown. Even among our own group of surgeons, the less-invasive approach has not been adopted universally.

A paramedian incision for AVR was introduced in $1996^{2}$; subsequently, a partial upper J-incision (hereafter referred to simply as "J-incision"), introduced in $1997,{ }^{3}$ has been gaining acceptance..$^{2-5} \mathrm{We}^{5}$ and others ${ }^{1-3,5-10}$ have reported that the J-incision has multiple benefits compared with a standard median sternotomy, including less surgical trauma, less pain, shorter ventilation time, and shorter intensive care unit (ICU) and hospital lengths of stay. ${ }^{2-10}$ Because of these possible advantages, a J-incision might 


\section{Abbreviations and Acronyms \\ $\mathrm{AVR}=$ aortic valve replacement \\ $\mathrm{CABG}=$ coronary artery bypass grafting \\ CLD = chronic lung disease \\ FEV1 = forced expiratory volume in 1 second \\ FEV $1 \%=$ forced expiratory volume in 1 second, percent of predicted \\ ICU = intensive care unit}

be beneficial for high-risk patients, such as those with pulmonary dysfunction, a well-established risk factor for mortality and morbidity after cardiac surgery. ${ }^{5,11,12}$

The J-incision may stabilize the sternum and thoracic cage, resulting in better postoperative pulmonary function. ${ }^{3-5}$ Furthermore, it is believed that less spreading of the incision, not interfering with the diaphragm, and less tissue dissection might facilitate earlier postoperative respiratory recovery. ${ }^{5,13}$ Yet these perceived benefits have not been studied in the specific high-risk group of patients with pulmonary dysfunction. ${ }^{3,4,6-14}$

Such a study is challenging because pulmonary dysfunction comprises a broad spectrum of lung diseases and is complex to define. Spirometry is the most common pulmonary function test used to assess severity and operative risks in these patients. ${ }^{15}$ It is not influenced by observer bias and provides markers for degree of lung function impairment. Therefore, we investigated whether a J-incision for AVR leads to more favorable outcomes in patients with pulmonary dysfunction, using forced expiratory volume in $1 \mathrm{sec}-$ ond, percent of predicted (FEV1\%), as a surrogate.

\section{PATIENTS AND METHODS \\ Patients}

From January 1995 to July 2010, 6931 patients underwent primary isolated AVR, of whom 655 had preoperative spirometry data available (J-incision in 368 and full sternotomy in 287). Patients undergoing concomitant mitral valve surgery or coronary artery bypass grafting (CABG) were excluded, as were those with active endocarditis. Mean age was $68 \pm 13$ years, and $54 \%$ were men.

\section{Data}

Data were retrieved from the prospective Cardiovascular Information Registry, supplemented with information from the Echocardiography database. Preoperative spirometry data were obtained from the institution's prospectively recorded Pulmonary Function Laboratory database. Preoperative forced expiratory volume in 1 second (FEV1) and forced vital capacity values were normalized to percent of predicted by the National Health and Nutrition Examination Survey algorithm. ${ }^{16}$ All data were approved for use in research by the Institutional Review Board, with patient consent waived.

\section{Surgical Technique}

Conventional general anesthesia was used in all patients regardless of surgical approach. Patients who underwent less-invasive J-incision had an 8 - to 10-cm skin incision. The upper sternum was divided in the midline, and this sternotomy was extended into the right fourth intercostal space forming a J. ${ }^{3,4}$ The diaphragm was not interfered with, and spreading the incision was limited to approximately $5 \mathrm{~cm}$, minimizing tension and flexing of the posterior rib attachments to the vertebral bodies. Approach to the aortic valve was via an oblique aortotomy carried into the noncoronary cusp or a transverse aortotomy above the sinutubular junction, and choice of valve type was at the discretion of the surgeon. AVR was then carried out according to the surgeon's standard technique.

Vacuum-assisted cardiopulmonary bypass with central cannulation was used in all patients. Intraoperative transfusions, anesthetic technique, and timing of extubation were at the anesthesiologists' and critical care team's discretion. Intraoperative and postoperative transfusions were not driven by protocolized transfusion triggers, except that Cleveland Clinic has long advocated blood-conservation practices.

\section{Outcomes}

Outcomes assessed included intraoperative support (myocardial ischemic time, cardiopulmonary bypass time), postoperative in-hospital mortality and morbidity (defined in accordance with the Society of Thoracic Surgeons National Database: http://www.ctsnet.org/file/ rptDataSpecifications252_1_ForVendorsPGS.pdf), blood product use, time to extubation, ICU and postoperative lengths of stay, and longterm survival.

Survival was assessed by active follow-up at 2 years and then every 5 years using an Institutional Review Board-approved questionnaire with patient consent required. Vital status was supplemented with data from the Social Security Death Master File with a censoring date of February 15, 2011. A total of 2423 patient-years of combined active and passive follow-up for vital status were available for analysis, with a median follow-up of 2.7 years; $25 \%$ of survivors were followed more than 6.1 years, and $10 \%$ were followed more than 9.2 years. Thus, survival curves are truncated at 10 years. The seemingly short median follow-up is caused by a combination of an escalating volume of AVRs in recent years ${ }^{5}$ and increased use of preoperative spirometry (Figure E1).

\section{Data Analysis}

All analyses were performed using SAS statistical software (v9.1; SAS Institute Inc, Cary, NC).

\section{Spirometry and Chronic Lung Disease}

Trends in spirometry values according to clinical diagnosis of CLD were estimated by logistic regression analysis, as were factors associated with performing preoperative spirometry.

\section{Factors Associated With Surgical Approach}

A number of patient characteristics differed between those receiving a less-invasive J-incision and those undergoing full sternotomy, including spirometry data (Table 1). Logistic regression analysis was used to identify statistically significant preoperative differences. A parsimonious model was developed using bagging. ${ }^{17,18}$ Briefly, a patient is selected at random to begin building a new data set, and this random selection process is repeated until the new data set is the same size as the original. On average, approximately one third of patients are not selected, and therefore a number of patients are duplicated. This is known as a bootstrap sample; 1000 such bootstrap data sets were built. Each was then analyzed by automated stepwise regression with a $P$ value criterion to retain of .05 using the candidate risk factors listed in Appendix E1. This resulted in 1000 regression models. These models were then aggregated by counting the frequency of occurrence of variables in the 1000 models. We consolidated counts of closely correlated variables such as linearizing transformations of scale. We then selected variables for the final model if they appeared in $50 \%$ or more of the analyses (a measure of reliability). 
TABLE 1. Patient characteristics and operative details by surgical approach

\begin{tabular}{|c|c|c|c|c|c|c|c|c|}
\hline \multirow[b]{3}{*}{ Variable } & \multicolumn{4}{|c|}{ All patients } & \multicolumn{4}{|c|}{ Propensity-matched patients } \\
\hline & \multicolumn{2}{|c|}{$J$-incision $(n=368)$} & \multicolumn{2}{|c|}{ Full $(\mathbf{n}=287)$} & \multicolumn{2}{|c|}{ J-incision $(n=223)$} & \multicolumn{2}{|c|}{ Full $(\mathbf{n}=\mathbf{2 2 3})$} \\
\hline & $\mathbf{n}^{*}$ & $\begin{array}{l}\text { No. }(\%) \text { or } \\
\text { mean } \pm \text { SD }\end{array}$ & $\mathbf{n}^{*}$ & $\begin{array}{l}\text { No. }(\%) \text { or } \\
\text { mean } \pm \text { SD }\end{array}$ & $\mathbf{n}^{*}$ & $\begin{array}{l}\text { No. }(\%) \text { or } \\
\text { mean } \pm \text { SD }\end{array}$ & $\mathbf{n}^{*}$ & $\begin{array}{l}\text { No. }(\%) \text { or } \\
\text { mean } \pm \text { SD }\end{array}$ \\
\hline \multicolumn{9}{|l|}{ Demography } \\
\hline Women & 368 & $177(48)$ & 287 & $126(44)$ & 223 & $105(47)$ & 223 & $104(47)$ \\
\hline Age (y) & 368 & $69 \pm 12$ & 287 & $67 \pm 13$ & 223 & $67 \pm 13$ & 223 & $68 \pm 13$ \\
\hline $\mathrm{BMI}\left(\mathrm{kg} \cdot \mathrm{m}^{-2}\right)$ & 349 & $30 \pm 7.2$ & 261 & $30 \pm 8.0$ & 208 & $30 \pm 7.6$ & 203 & $31 \pm 8.0$ \\
\hline NYHA functional class & 288 & & 225 & & 174 & & 172 & \\
\hline I & & $54(19)$ & & $36(16)$ & & $32(18)$ & & $31(18)$ \\
\hline II & & $145(50)$ & & $114(51)$ & & $89(51)$ & & $85(49)$ \\
\hline III & & $80(28)$ & & $67(30)$ & & $45(26)$ & & $52(30)$ \\
\hline IV & & $9(3.1)$ & & $8(3.6)$ & & $8(4.6)$ & & $4(2.3)$ \\
\hline Indication for operation & 366 & & 285 & & 222 & & 222 & \\
\hline Degenerative & & $360(98)$ & & $268(94)$ & & $216(97)$ & & $209(94)$ \\
\hline Other & & $6(1.6)$ & & $17(6.0)$ & & $6(2.7)$ & & $13(5.8)$ \\
\hline \multicolumn{9}{|l|}{ Cardiac comorbidity } \\
\hline $\operatorname{LVEF}(\%)$ & 358 & $56 \pm 8.7$ & 281 & $52 \pm 14$ & 217 & $56 \pm 9.0$ & 218 & $55 \pm 11$ \\
\hline Aortic valve area $\left(\mathrm{cm}^{2}\right)$ & 326 & $0.7 \pm 0.2$ & 226 & $0.7 \pm 0.4$ & 192 & $0.7 \pm 0.2$ & 184 & $0.7 \pm 0.2$ \\
\hline \multicolumn{9}{|l|}{ Aortic valve gradient ( $\mathrm{mm} \mathrm{Hg}$ ) } \\
\hline Mean & 334 & $48 \pm 16$ & 245 & $47 \pm 18$ & 197 & $48 \pm 16$ & 196 & $47 \pm 17$ \\
\hline Peak & 334 & $82 \pm 23$ & 245 & $80 \pm 29$ & 197 & $82 \pm 24$ & 196 & $81 \pm 28$ \\
\hline $\mathrm{LV}$ mass index $\left(\mathrm{g} \cdot \mathrm{m}^{-2}\right)$ & 327 & $118 \pm 36$ & 240 & $136 \pm 45$ & 193 & $125 \pm 38$ & 187 & $126 \pm 39$ \\
\hline LA volume index $\left(\mathrm{mL} \cdot \mathrm{m}^{-2}\right)$ & 316 & $18 \pm 10$ & 229 & $21 \pm 11$ & 184 & $19 \pm 11$ & 180 & $19 \pm 11$ \\
\hline $\begin{array}{l}\text { Tricuspid regurgitation more } \\
\text { than moderate }\end{array}$ & 343 & $43(12)$ & 271 & $24(8.8)$ & 214 & $25(12)$ & 209 & $16(7.6)$ \\
\hline Atrial fibrillation/flutter & 346 & $17(4.9)$ & 257 & $7(2.7)$ & 207 & $9(4.3)$ & 199 & $7(3.5)$ \\
\hline \multicolumn{9}{|l|}{ Noncardiac comorbidity } \\
\hline Hypertension & 368 & $255(69)$ & 287 & $200(70)$ & 223 & $157(70)$ & 223 & $157(70)$ \\
\hline CLD & 368 & $133(36)$ & 287 & $117(41)$ & 223 & $86(39)$ & 223 & $88(39)$ \\
\hline Past or current smoking & 367 & $238(65)$ & 286 & $183(64)$ & 223 & $141(63)$ & 223 & $149(67)$ \\
\hline FEV1\% & 368 & $84 \pm 23$ & 287 & $78 \pm 21$ & 223 & $80 \pm 21$ & 223 & $80 \pm 21$ \\
\hline FVC $(\%$ of predicted $)$ & 368 & $89 \pm 20$ & 287 & $81 \pm 19$ & 223 & $85 \pm 20$ & 223 & $83 \pm 19$ \\
\hline FEV1/FVC & 368 & $70 \pm 12$ & 287 & $72 \pm 11$ & 223 & $71 \pm 12$ & 223 & $72 \pm 11$ \\
\hline
\end{tabular}

$S D$, Standard deviation; $B M I$, body mass index; $N Y H A$, New York Heart Association; $L V E F$, left ventricular ejection fraction; $L V$, left ventricle; $L A$, left atrial; $C L D$, chronic lung disease; $F E V 1 \%$, forced expiratory volume in 1 second, percent of predicted; $F V C$, forced vital capacity; $F E V I$, forced expiratory volume in 1 second. *Number of patients with data available.

\section{Propensity Score Development and Use}

To reduce the influence of selection bias for surgical approach, we used propensity matching. ${ }^{19}$ After establishing the parsimonious model for approach (Table E1), we added other variables, identified in Appendix E1, representing groups of patient factors that might be related to unrecorded selection factors (saturated model). A propensity score was then calculated for each patient by solving the saturated model for the probability of undergoing a full sternotomy versus a J-incision.

By using only the propensity score, 223 patients (78\%) who received a J-incision were matched to patients who received a full sternotomy using a greedy matching strategy. These matched patients spanned the majority of patients (Figure E2, A), although patients with extreme propensity scores (strongly favoring J-incision or strongly favoring full sternotomy) represent unmatched patients whose propensity scores deviated more than 0.2 from those of patients receiving a full sternotomy. The result was 2 groups of patients well matched for characteristics (Table 1 and Figure E2, B). In addition, because the number of events was insufficient to perform an extensive multivariable analysis, the propensity score itself was used additionally as a risk-adjustment factor for analyses of survival. ${ }^{20}$

\section{Managing Missing Covariable Data}

We used 5-fold multiple imputation using a Markov Chain Monte Carlo technique to impute missing covariable values in multivariable analyses (SAS PROC MI, SAS Institute, Inc). The first imputation data set was used for model development, followed by fitting the final model to each of the other 4 data sets and then aggregating the results (SAS PROC MIANALYZE, SAS Institute, Inc).

\section{Comparisons}

Continuous variables were compared using the Wilcoxon rank-sum test. Categoric variables were compared using the chi-square test or Fisher exact test when frequency was less than 5 .

The unadjusted relationship of FEV1\% and intubation time, ICU length of stay, and postoperative length of stay was characterized semiparametrically using spline smoothing, stratified by surgical approach (SPlus v8.04, 2007, Insightful Corp, Seattle, Wash). The resulting smoothed curves for these outcomes were superimposed on box plots for 4 equal intervals according to approach. Each relation was adjusted for preoperative variables (Appendix E1) using linear regression and bagging as described earlier. 
Nonparametric survival estimates were obtained by the Kaplan-Meier method and parametrically by a multiphase hazard model. ${ }^{21}$ (For additional details, see http://my.clevelandclinic.org/professionals/software/hazard/ default.aspx). The parametric model was used to resolve a number of phases of instantaneous risk of death (hazard function) and to estimate shaping parameters. Risk factors for each hazard phase were identified simultaneously using bagging, as described previously.

\section{Presentation}

Continuous variables are summarized as mean \pm standard deviation and as 15 th, 50th (median), and 85 th percentiles for skewed data distributions. Categoric variables are summarized by frequencies and percentages. Parametric estimates are accompanied by asymmetric $68 \%$ confidence bands, comparable to \pm 1 standard error.

\section{RESULTS}

\section{Preoperative Spirometry and History of Chronic Lung Disease}

Preoperative spirometry was performed in only $10 \%$ to $15 \%$ of patients before 2006 , but since then that proportion has increased to $30 \%$ to $45 \%$ (Figure E1). Spirometry was performed preferentially in patients with a history of smoking, clinical diagnosis of CLD, or higher risk (Tables E2 and E3).

Lower spirometry values were progressively more strongly associated with clinical history of CLD (Figure E3). FEV1\% was more discriminating than forced vital capacity percent of predicted (lung-diffusing capacity was available for only a minority of patients). Lower FEV1\% also was associated with older age, history of smoking, heart failure, atrial fibrillation, kidney dysfunction, smaller aortic valve area, and lower ejection fraction (Table E4).

\section{Preoperative Spirometry and Surgical Approach}

Preoperative spirometry was strongly related to surgical approach (Table 1), with full sternotomy apparently preferred for patients with poorer respiratory function. Full sternotomy also was more common in patients with heart failure, lower ejection fraction, impaired hepatic function, and greater left ventricular mass (Table E1).

\section{Intubation Time}

Preoperative FEV1\% was not correlated with duration of intubation, either unadjusted $(P=.2)$ or adjusted for preoperative variables $(P=.4)$ (Figure $1, A)$. Patients in the full sternotomy group had a higher occurrence of respiratory insufficiency (intubated $>24$ hours) than the propensitymatched $\mathrm{J}$-incision group ( $10 \%$ vs $5.1 \%, P=.06$; Table 2 ), although mean duration of intubation was similar $(15 \pm 6.3$ hours vs $14 \pm 6.5$ hours, respectively, $P=.4$; Table 2 ).

\section{Length of Intensive Care Unit Stay}

Patients with lower preoperative FEV1\% had more prolonged ICU stays $(P=.0002$ unadjusted, $P<.0001$ adjusted
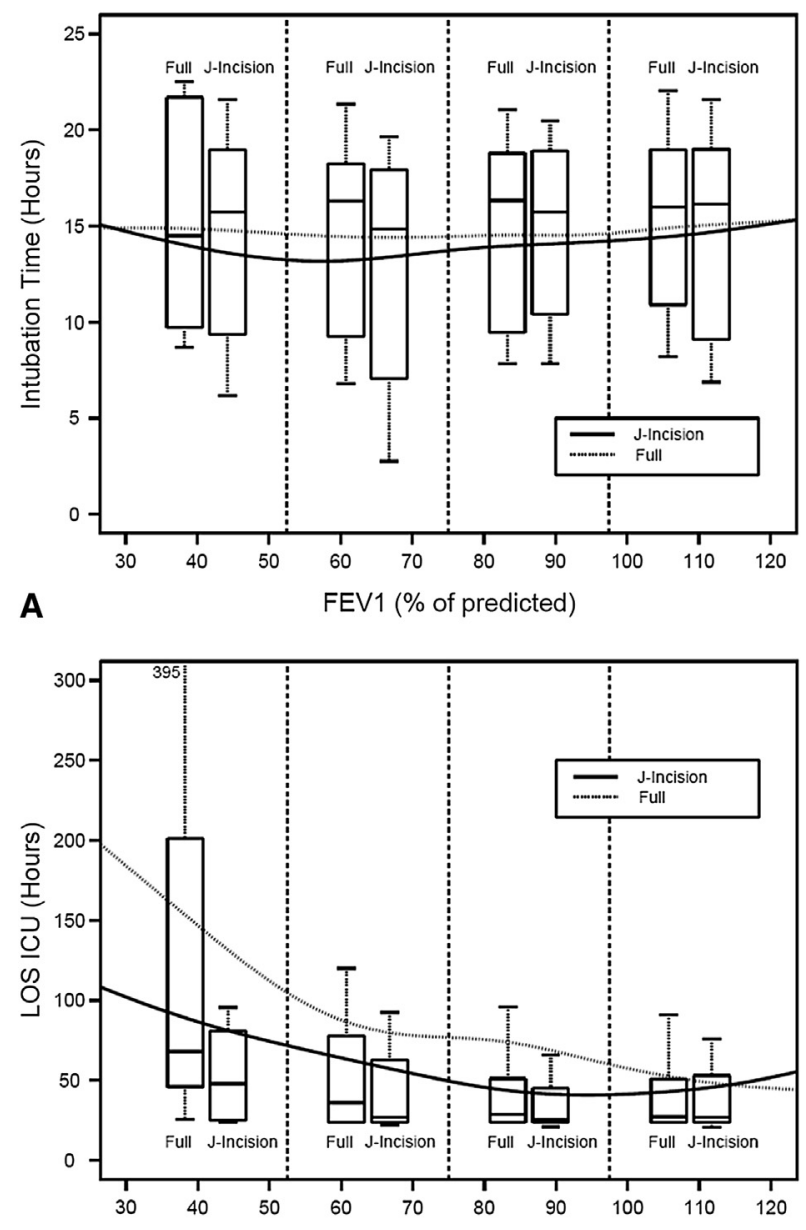

B FEV1 (\% of predicted)

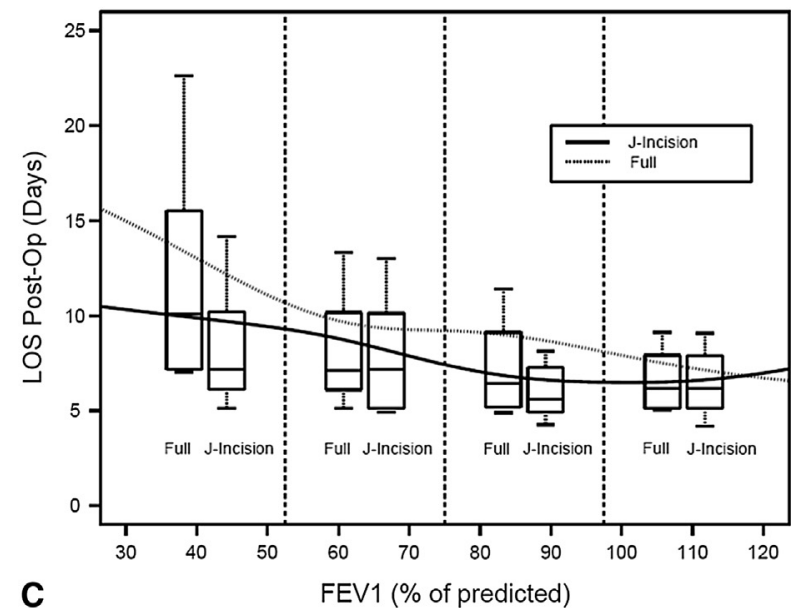

FIGURE 1. Relationship of FEV1\% to intubation time and ICU and postoperative (Post-Op) lengths of stay. Box plots show 15th, 25th, 50th, 75th, and 85 th percentiles of data points for 4 equal intervals of FEV1\% values stratified by surgical approach. Solid lines represent spline fits for the J-incision group, and dashed lines represent fits for the full sternotomy group. A, FEV $1 \%$ and intubation time (hours). B, FEV1\% and ICU stay. C, FEV $1 \%$ and postoperative stay. FEVI, Forced expiratory volume in 1 second; $I C U$, intensive care unit; $L O S$, length of stay. 
TABLE 2. In-hospital outcomes by surgical approach, overall and in propensity-matched patients*

\begin{tabular}{|c|c|c|c|c|c|c|c|c|c|c|}
\hline \multirow[b]{3}{*}{ Outcome } & \multicolumn{5}{|c|}{ Overall } & \multicolumn{5}{|c|}{ Propensity-matched } \\
\hline & \multicolumn{2}{|c|}{$\begin{array}{l}\text { J-incision } \\
(\mathbf{n}=\mathbf{3 6 8})\end{array}$} & \multicolumn{2}{|c|}{$\begin{array}{c}\text { Full sternotomy } \\
(\mathbf{n}=\mathbf{2 8 7})\end{array}$} & \multirow[b]{2}{*}{$P$} & \multicolumn{2}{|c|}{$\begin{array}{r}\text { J-incision } \\
(\mathbf{n}=\mathbf{2 2 3}) \\
\end{array}$} & \multicolumn{2}{|c|}{$\begin{array}{l}\text { Full sternotomy } \\
(\mathbf{n}=\mathbf{2 2 3})\end{array}$} & \multirow[b]{2}{*}{$P$} \\
\hline & No. & $\%$ & No. & $\%$ & & No. & $\%$ & No. & $\%$ & \\
\hline Intubation time $(\mathrm{h}) \dagger$ & \multicolumn{2}{|c|}{$14 \pm 6.4$} & \multicolumn{2}{|c|}{$15 \pm 6.2$} & .3 & \multicolumn{2}{|c|}{$14 \pm 6.5$} & \multicolumn{2}{|c|}{$15 \pm 6.3$} & .4 \\
\hline ICU length of stay (h) $\ddagger$ & \multicolumn{2}{|c|}{$22 / 27 / 78$} & \multicolumn{2}{|c|}{$24 / 31 / 120$} & .0007 & \multicolumn{2}{|c|}{$22 / 26 / 79$} & \multicolumn{2}{|c|}{$24 / 29 / 96$} & .02 \\
\hline Postoperative length of stay (d) $\ddagger$ & \multicolumn{2}{|c|}{$5 / 6 / 10$} & \multicolumn{2}{|c|}{$5 / 7 / 12$} & $<.0001$ & \multicolumn{2}{|c|}{$5 / 6 / 10$} & \multicolumn{2}{|c|}{$5 / 7 / 11$} & .01 \\
\hline Respiratory insufficiency & 16 & 5.3 & 30 & 14 & .0005 & 9 & 5.1 & 18 & 10 & .06 \\
\hline Stroke & 3 & 0.82 & 2 & 0.69 & .9 & 2 & 0.89 & 2 & 0.89 & $>.9$ \\
\hline Renal failure & 9 & 2.4 & 16 & 5.6 & .04 & 6 & 2.7 & 9 & 4.0 & .4 \\
\hline Myocardial infarction & 0 & 0 & 0 & 0 & - & 0 & 0 & 0 & 0 & - \\
\hline Deep sternal wound infection & 2 & 0.54 & 2 & 0.69 & .8 & 2 & 0.89 & 0 & 0 & .2 \\
\hline Sepsis/septicemia & 4 & 1.1 & 6 & 2.1 & .3 & 4 & 1.8 & 4 & 1.8 & $>.9$ \\
\hline Return to OR for bleeding & 11 & 3.0 & 11 & 3.8 & .6 & 7 & 3.1 & 9 & 4.0 & 6 \\
\hline Death & 2 & 0.54 & 6 & 2.1 & .07 & 2 & 0.89 & 4 & 1.8 & .4 \\
\hline
\end{tabular}

$I C U$, Intensive care unit; $O R$, operating room. *Morbidities as defined by and submitted to the Society of Thoracic Surgeons Adult Cardiac National Database. $\dagger$ Mean \pm standard deviation. $\ddagger 15$ th $/ 50$ th $/ 85$ th percentiles.

for preoperative variables; Figure 1, B). Length of ICU stay was longer in the full sternotomy group (median, 29 hours) than in the propensity-matched J-incision group (median, 26 hours; $P=.02$; Table 2).

\section{Length of Postoperative Stay}

Patients with lower preoperative FEV1\% had more prolonged postoperative stays $(P<.0001$ unadjusted and adjusted for preoperative variables; Figure $1, C$ ). Length of postoperative stay was longer in the full sternotomy group (median, 7 days) than in the matched J-incision group (median, 6 days; $P=.01$; Table 2).

\section{Hospital Mortality and Complications}

Among propensity-matched patients, hospital mortality ( $1.8 \%$ full sternotomy vs $0.89 \% \mathrm{~J}$-incision) and morbidity were similar for patients with a full sternotomy and those with a J-incision (Table 2).

\section{Survival}

Patients with lower preoperative FEV1\% had lower propensity-adjusted survival (Figure 2, $A$ and Table 3). This was particularly apparent in the full sternotomy group, with confidence bands separating below an FEV1\% of approximately 50 . However, by 5 years, these curves converged (Figure $2, B$ ). Unadjusted survival was lower in the early hazard phase after full sternotomy than after J-incision; survival estimates at 6 months and 1, 5, and 10 years were $89 \%, 87 \%, 73 \%$, and $48 \%$ in the full sternotomy group versus $95 \%, 94 \%, 80 \%$, and $55 \%$ in the J-incision group, respectively (Figure E4). Risk-adjusted survival was more similar (Figure E5), with the important interaction of approach with FEV1\% as noted in Table 3 and Figure 2. Thus, lower preoperative FEV1\% was an incremental risk factor in the early hazard phase and both lower
FEV $1 \%$ and full sternotomy in the late hazard phase, with J-incision protective.

\section{DISCUSSION \\ Principal Findings}

This study has shown that with increasingly poor pulmonary function, as measured by FEV1\%, patients with CLD derive a greater benefit from undergoing a less-invasive J-incision for AVR than AVR performed through a full sternotomy. This is reflected in the results showing that postoperative respiratory insufficiency, defined as intubation for more than 24 hours, was twice as high for full sternotomy, and ICU and postoperative lengths of stay were longer, particularly in patients with lower FEV1\%. Furthermore, hospital mortality was twice as high for full sternotomy, and later survival was worse, especially among patients with low FEV1\%. Indeed, the lower the FEV1\%, the better the 1-year survival for those undergoing a less-invasive J-incision compared with those undergoing full sternotomy. Even to 10 years, patients receiving a J-incision maintained an approximate survival advantage of $8 \%$, both unadjusted and after propensity matching. Thus, this article confirms for the first time the theoretic advantage of less interference with respiratory function using the less-invasive approach, and this is reflected in better respiratory outcomes and survival, particularly in high-risk patients with poor respiratory function.

\section{Clinical Implications}

Pulmonary dysfunction in patients with CLD is a welldocumented risk factor for morbidity and mortality after cardiac surgery. Analyses of large cardiac registries have reported increased odds of in-hospital mortality by ratios of 1.4 to 1.6 among patients with versus without CLD. ${ }^{22-26}$ Reduction of lung function postoperatively is influenced 

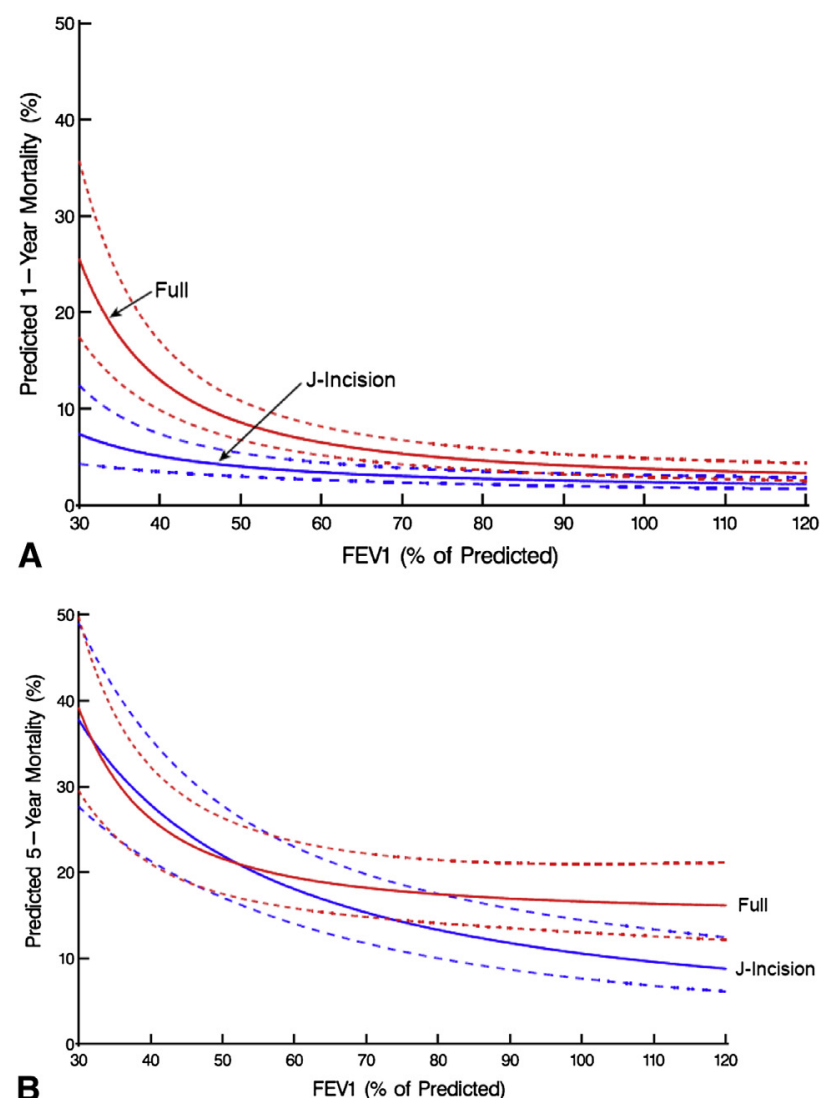

FIGURE 2. Nomograms of 1- and 5-year risk-adjusted mortality according to preoperative FEV1\% stratified by approach. These nomograms represent solutions to the multivariable equation found in Table 3. A, Predicted 1-year mortality. B, Predicted 5-year mortality. FEV1, Forced expiratory volume in 1 second.

not only by use of extracorporeal circulation but also by length of the sternal incision. ${ }^{13,22,23}$ Trauma to the sternum, use of internal thoracic artery for bypass grafting, opening the pleura, and placing chest tubes may affect postoperative pulmonary function, especially in patients with poor pulmonary reserve. ${ }^{27}$

Thus, surgical strategies should be modified in patients with pulmonary dysfunction. Use of a J-incision may stabilize the sternum and thoracic cage, resulting in better postoperative pulmonary function and ability to cough and breath. $^{3,4,6,13}$ This advantage may be the result of less surgical dissection, less spreading of the sternum, and minimizing tension on the posterior rib head and costovertebral ligaments, because the chest wall is not opened like a trap door. Further, there is no interference with the diaphragm or dissection along it. Also, with less chest wall pain, patients may have less splinting of the chest and thus breathe more deeply. Meta-analysis has shown shorter intubation times after the J-incision approach. ${ }^{9}$

We showed previously in a propensity-matched comparison that a substantially higher proportion of matched
TABLE 3. Incremental risk factors for death after aortic valve replacement, with propensity for full sternotomy forced into model*

\begin{tabular}{lll}
\hline \multicolumn{1}{c}{ Factor } & Coefficient \pm SE & \multicolumn{1}{c}{$\boldsymbol{P}$} \\
\hline Early hazard phase & & \\
Lower FEV1\% $\dagger$ & $1.13 \pm 0.30$ & .0002 \\
J-incision & $0.37 \pm 0.85$ & .7 \\
J-incision/FEV1\% interaction & $0.69 \pm 0.63$ & .3 \\
Propensity for full sternotomy & $0.94 \pm 0.71$ & .18 \\
Late hazard phase & & \\
Lower FEV1\% $\ddagger$ & $1.31 \pm 0.48$ & .007 \\
J-incision & $5.61 \pm 2.95$ & .06 \\
Full sternotomy/FEV1\% interaction & $1.34 \pm 0.70$ & .06 \\
Propensity for J-incision & $0.23 \pm 0.62$ & .7 \\
\hline
\end{tabular}

$S E$, Standard error; $F E V 1 \%$, forced expiratory volume in 1 second, percent of predicted. *Adjusted for age, body mass index, New York Heart Association functional class, aortic valve peak gradient, tricuspid valve regurgitation, peripheral arterial disease, previous stroke, diabetes, and blood urea nitrogen. $\dagger(\text { FEV1\%/81) })^{-1}$, inverse

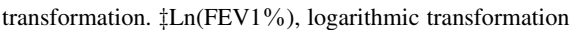

patients were extubated in the operating room after a J-incision than after full sternotomy $(12 \%$ vs $1.6 \%$, $P<.0001){ }^{5}$ Median time to extubation was also shorter (5.2 hours [confidence limit, 2.5-12] vs 6.9 hours [confidence limit, 3.6-21], $P<.0001)$. FEV1\% was higher immediately after extubation in the J-incision group, with the difference narrowing during the first 36 hours after surgery. Of note, risk of respiratory failure was lower with the $\mathrm{J}$-incision $(P=.01)$.

These results confirm the need to modify our surgical strategies for patients with severe pulmonary dysfunction who are at high risk for postoperative morbidity and mortality after full sternotomy. This risk has been demonstrated repeatedly in patients undergoing CABG. Canver and colleagues $^{24}$ identified preoperative FEV1\% as an important predictor of 5-year survival in patients with CLD undergoing CABG. Preoperative FEV1 of less than 1.25 carried a 7-fold higher risk of death during follow-up, with 9-year survival of $42 \%$ versus $76 \%$ for those with higher FEV1. Other studies have shown similar in-hospital mortality for patients with mild to moderate CLD and worse outcomes among those with severe CLD. ${ }^{25}$ Fuster and colleagues ${ }^{26}$ have demonstrated that operative mortality after CABG is related to severity of CLD; mortality was $0.4 \%$ to $0.9 \%$ in patients with FEV $1 \%$ more than $60 \%$, but $11 \%$ for FEV $1 \%$ of $40 \%$ to $59 \%$ and $54 \%$ for FEV1\% less than $40 \%$.

Clinical implications are that the less-invasive J-incision should be encouraged rather than avoided for high-risk patients with pulmonary disease. We therefore recommend this approach for these patients.

\section{Study Limitations}

Investigation of the influence of chronic obstructive pulmonary disease or CLD on survival and morbidity after 
cardiac surgery is confounded by definitions and ability to measure degree of dysfunction. We chose to use FEV1\% as a surrogate, fully aware that other tests, such as lung diffusion capacity testing and arterial blood gases, may have added to the study's predictive abilities. However, these tests were not routinely available. Ideally, a randomized trial between the less-invasive J-incision and full sternotomy should be performed in high-risk patients with severe pulmonary dysfunction. On the basis of our experience with this population, however, including the transcatheter AVR trials, ${ }^{1}$ we do not have equipoise for such a trial.

We used propensity matching to compare patients receiving J-incision with those undergoing full sternotomy. However, propensity methods address only that portion of the spectrum for which heterogeneity in practice is discovered (virtual equipoise). As with randomized trials, it is tempting to extrapolate beyond the confines of the overlapping portions of the spectrum. Furthermore, at both extremes of the spectrum, surgeons at the Cleveland Clinic during the period of this study systematically performed J-incision or full sternotomy for AVR. We acknowledge that selection bias cannot be completely reversed by propensity-based methods and, in this study, cannot completely overcome distinct surgeon preferences, although we attempted to adjust for these. Treatment was not masked, and this could have influenced ICU critical care management to an unmeasurable extent.

This is also a single-institution study conducted at a highvolume center, which may have decreased the differences in outcomes between the 2 strategies and may limit its generalizability. Nevertheless, time to extubation and spirometry values would largely have been uninfluenced by potential surgeon biases because these were determined or routinely collected by respiratory therapists, anesthesiologists, interventionists, or nurses.

\section{CONCLUSIONS}

For patients with severe respiratory dysfunction, a lessinvasive partial upper J-incision for AVR can lead to more favorable outcomes than full sternotomy, including shorter ICU and postoperative lengths of stay and better early survival, which are amplified with decreasing pulmonary function.

\section{References}

1. Svensson LG, Tuzcu M, Kapadia S, Blackstone EH, Roselli EE, Gillinov AM, et al. A comprehensive review of the PARTNER trial. J Thorac Cardiovasc Surg. 2013;145(suppl):S11-6.

2. Cosgrove DM III, Sabik JF. Minimally invasive approach for aortic valve operations. Ann Thorac Surg. 1996;62:596-7.

3. Svensson LG. Minimal-access "J" or "j" sternotomy for valvular, aortic, and coronary operations or reoperations. Ann Thorac Surg. 1997;64:1501-3.
4. Cohn LH, Adams DH, Couper GS, Bichell DP, Rosborough DM, Sears SP, et al. Minimally invasive cardiac valve surgery improves patient satisfaction while reducing costs of cardiac valve replacement and repair. Ann Surg. 1997;226:421-8.

5. Johnston DR, Atik FA, Rajeswaran J, Blackstone EH, Nowicki ER, Sabik F Jr, et al. Outcomes of less invasive J-incision approach to aortic valve surgery. J Thorac Cardiovasc Surg. 2012;144:852-8.

6. Mihaljevic T, Cohn LH, Unic D, Aranki SF, Couper GS, Byrne JG. One thousand minimally invasive valve operations: early and late results. Ann Surg. 2004;240: 529-34.

7. Doll N, Borger MA, Hain J, Bucerius J, Walther T, Gummert JF, et al. Minimal access aortic valve replacement: effects on morbidity and resource utilization. Ann Thorac Surg. 2002;74:S1318-22.

8. Bakir I, Casselman FP, Wellens F, Jeanmart H, De Geest R, Degrieck I, et al. Minimally invasive versus standard approach aortic valve replacement: a study in 506 patients. Ann Thorac Surg. 2006;81:1599-604.

9. Brown ML, McKellar SH, Sundt TM, Schaff HV. Ministernotomy versus conventional sternotomy for aortic valve replacement: a systematic review and meta-analysis. J Thorac Cardiovasc Surg. 2009;137:670-9.e5.

10. Modi P, Hassan A, Chitwood WR Jr. Minimally invasive mitral valve surgery: a systematic review and meta-analysis. Eur J Cardiothorac Surg. 2008;34: 943-52.

11. Higgins TL, Estafanous FG, Loop FD, Beck GJ, Blum JM, Paranandi L. Stratification of morbidity and mortality outcome by preoperative risk factors in coronary artery bypass patients. A clinical severity score. JAMA. 1992;267:2344-8.

12. Roques F, Michel P, Goldstone AR, Nashef SA. The logistic EuroSCORE. Eur Heart J. 2003;24:881-2.

13. Bonacchi M, Prifti E, Giunti G, Frati G, Sani G. Does ministernotomy improve postoperative outcome in aortic valve operation? A prospective randomized study. Ann Thorac Surg. 2002;73:460-6.

14. Chitwood WR Jr, Wixon CL, Elbeery JR, Moran JF, Chapman WH, Lust RM. Video-assisted minimally invasive mitral valve surgery. $J$ Thorac Cardiovasc Surg. 1997;114:773-82.

15. Lung function testing: selection of reference values and interpretative strategies American Thoracic Society. Am Rev Respir Dis. 1991;144:1202-18.

16. Mannino DM, Buist AS, Petty TL, Enright PL, Redd SC. Lung function and mortality in the United States: data from the First National Health and Nutrition Examination Survey follow up study. Thorax. 2003;58:388-93.

17. Breiman L. Bagging predictors. Machine Learning. 1996;24:123-40.

18. Blackstone EH. Breaking down barriers: helpful breakthrough statistical methods you need to understand better. J Thorac Cardiovasc Surg. 2001;122: 430-9.

19. Rubin DB. The design versus the analysis of observational studies for causal effects: parallels with the design of randomized trials. Stat Med. 2007;26: 20-36.

20. Drake C, Fisher L. Prognostic models and the propensity score. Int J Epidemiol. 1995;24:183-7.

21. Blackstone EH, Naftel DC, Turner ME Jr. The decomposition of time-varying hazard into phases, each incorporating a separate stream of concomitant information. J Am Stat Assoc. 1986;81:615-24.

22. Hallfeldt KK, Siebeck M, Thetter O, Schweiberer L. The effect of thoracic surgery on pulmonary function. Am J Crit Care. 1995;4:352-4.

23. Shapira N, Zabatino SM, Ahmed S, Murphy DM, Sullivan D, Lemole GM. Determinants of pulmonary function in patients undergoing coronary bypass operations. Ann Thorac Surg. 1990;50:268-73.

24. Canver CC, Nichols RD, Kroncke GM. Influence of age-specific lung function on survival after coronary bypass. Ann Thorac Surg. 1998;66:144-7.

25. Samuels LE, Kaufman MS, Morris RJ, Promisloff R, Brockman SK. Coronary artery bypass grafting in patients with COPD. Chest. 1998;113:878-82.

26. Fuster RG, Argudo JA, Albarova OG, Sos FH, Lopez SC, Codoner MB, et al Prognostic value of chronic obstructive pulmonary disease in coronary artery bypass grafting. Eur J Cardiothorac Surg. 2006;29:202-9.

27. Berrizbeitia LD, Tessler S, Jacobowitz IJ, Kaplan P, Budzilowicz L, Cunningham JN. Effect of sternotomy and coronary bypass surgery on postoperative pulmonary mechanics. Comparison of internal mammary and saphenous vein bypass grafts. Chest. 1989;96:873-6. 


\section{APPENDIX E1. Variables used in analyses}

Demographics

Age $(\mathrm{y}),{ }^{*}$ sex,$*$ race, ${ }^{*}$ height $(\mathrm{cm})$, weight $(\mathrm{kg})$, body surface area $\left(\mathrm{m}^{2}\right)$, body mass index $\left(\mathrm{kg} \cdot \mathrm{m}^{-2}\right) *$

Preoperative symptoms

NYHA functional class (I-IV)*

Cardiac comorbidity

Complete heart block,* ventricular arrhythmia,* chronic heart failure,* previous cardiac operation

Noncardiac comorbidity

Hypertension,* peripheral arterial disease,* diabetes, ${ }^{*}$ stroke, ${ }^{*}$ smoking*

Laboratory medicine

Blood urea nitrogen $\left(\mathrm{mg} \cdot \mathrm{dL}^{-1}\right)$, total cholesterol $\left(\mathrm{mg} \cdot \mathrm{dL}^{-1}\right)$,* lowdensity lipoprotein $\left(\mathrm{mg} \cdot \mathrm{dL}^{-1}\right), *$ high-density lipoprotein $\left(\mathrm{mg} \cdot \mathrm{dL}^{-1}\right), *$ creatinine $\left(\mathrm{mg} \cdot \mathrm{dL}^{-1}\right),{ }^{*}$ hematocrit $(\%), *$ bilirubin $\left(\mathrm{mg} \cdot \mathrm{dL}^{-1}\right), *$ triglycerides $\left(\mathrm{mg} \cdot \mathrm{dL}^{-1}\right)$

Valve pathology

$\mathrm{AV}$ regurgitation, $\mathrm{AV}$ stenosis, ${ }^{*}$ mitral valve regurgitation, tricuspid valve regurgitation, AV native

AV etiology

Rheumatic, degenerative

LV size

LV end-diastolic volume (mL), ${ }^{*} \mathrm{LV}$ end-systolic volume $(\mathrm{mL}),{ }^{*} \mathrm{LV}$ diastolic diameter $(\mathrm{cm}), \mathrm{LV}$ systolic diameter $(\mathrm{cm}), \mathrm{LV}$ mass $(\mathrm{g})$, ${ }^{*}$ posterior wall thickness $(\mathrm{cm})$, septal thickness $(\mathrm{cm})$

LV function

Myocardial infarction,* ejection fraction (\%),* fractional shortening $(\%)^{*}$

Left atria

Left atrial diameter $(\mathrm{cm})$, left atrial volume $(\mathrm{mL}),{ }^{*}$ AV systolic area $\left(\mathrm{cm}^{2}\right), * \mathrm{AV}$ mean gradient $(\mathrm{mm} \mathrm{Hg}), *$ AV peak gradient $(\mathrm{mm} \mathrm{Hg}) *$

Spirometry

FEV1, percent of predicted*; FVC, percent of predicted; FEV1/FVC ratio*

Experience

Years since January 1, 1995*

NYHA, New York Heart Association; $A V$, aortic valve; $L V$, left ventricular; $F E V I$, forced expiratory volume in 1 second; $F V C$, forced vital capacity. *Variables included in propensity model.

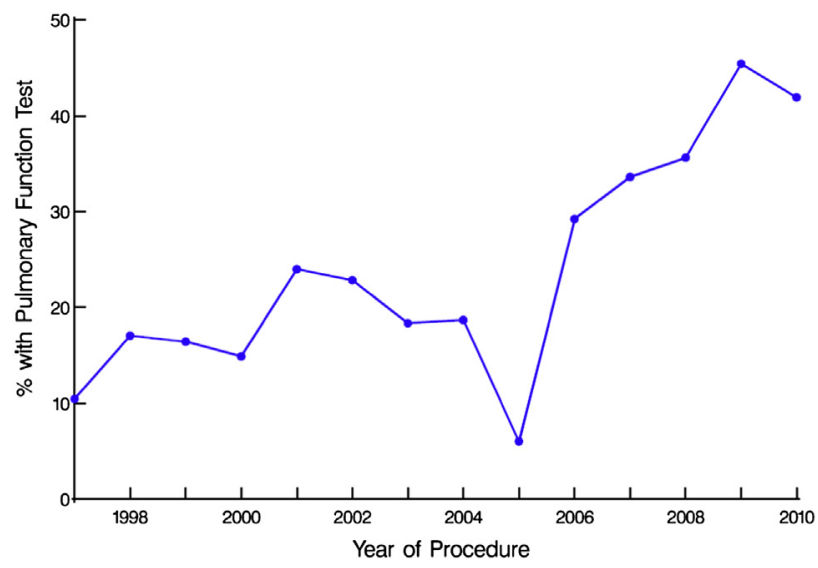

FIGURE E1. Preoperative spirometry testing over time, 1997 to 2010 $(\mathrm{n}=2619$, with 655 patients undergoing testing). 


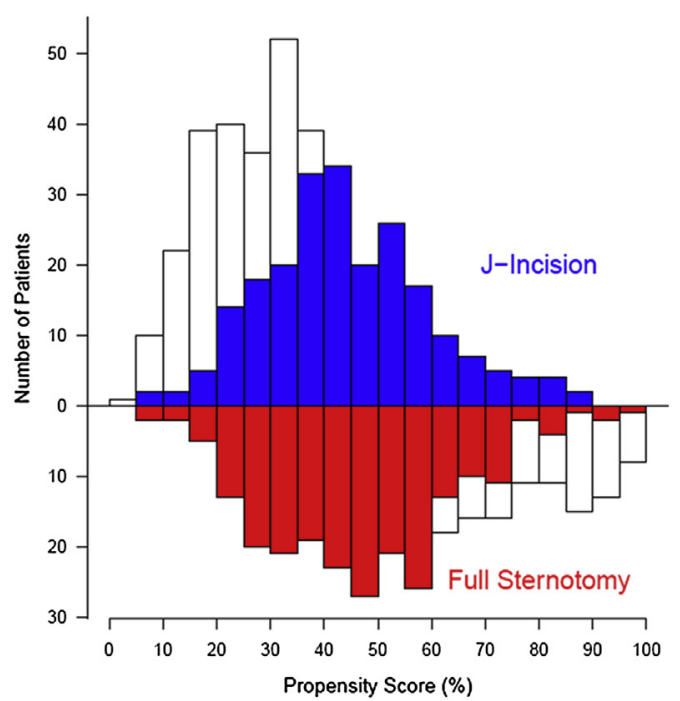

A

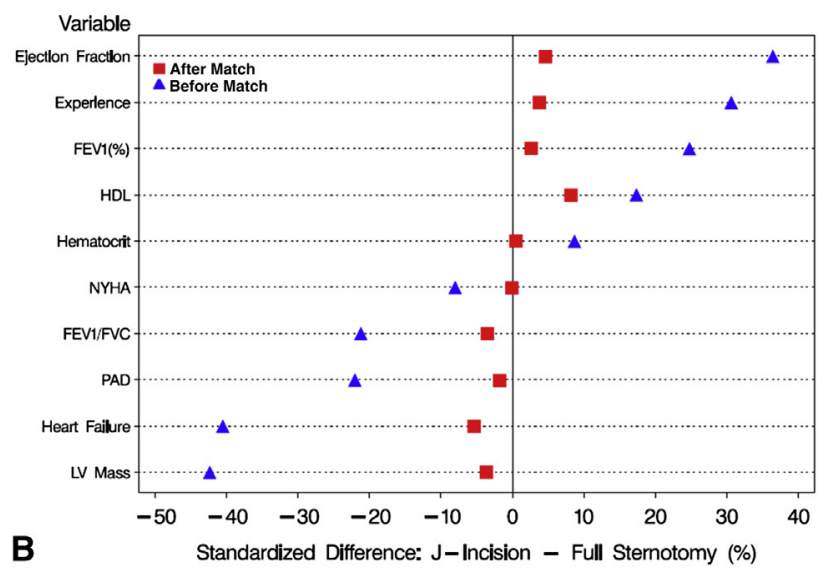

FIGURE E2. Propensity score matching for J-incision versus full sternotomy. A, Mirrored histogram of distribution of propensity scores for J-incision versus full sternotomy groups. Darkened area represents matched patient pairs. B, Covariable balance for selected variables before (closed triangles) and after (closed squares) propensity matching, expressed as standardized difference. ${ }^{1}$ NYHA, New York Heart Association; FEV1, forced expiratory volume in 1 second; $F E V 1 \%$, forced expiratory volume in 1 second, percent of predicted; $F V C$, forced vital capacity; $H D L$, highdensity lipoprotein; $L V$, left ventricular; $P A D$, peripheral arterial disease. 1. Austin PC, Mamdani MM. A comparison of propensity score methods: a case-study estimating the effectiveness of post-AMI statin use. Stat Med. 2006;25:2084-106.
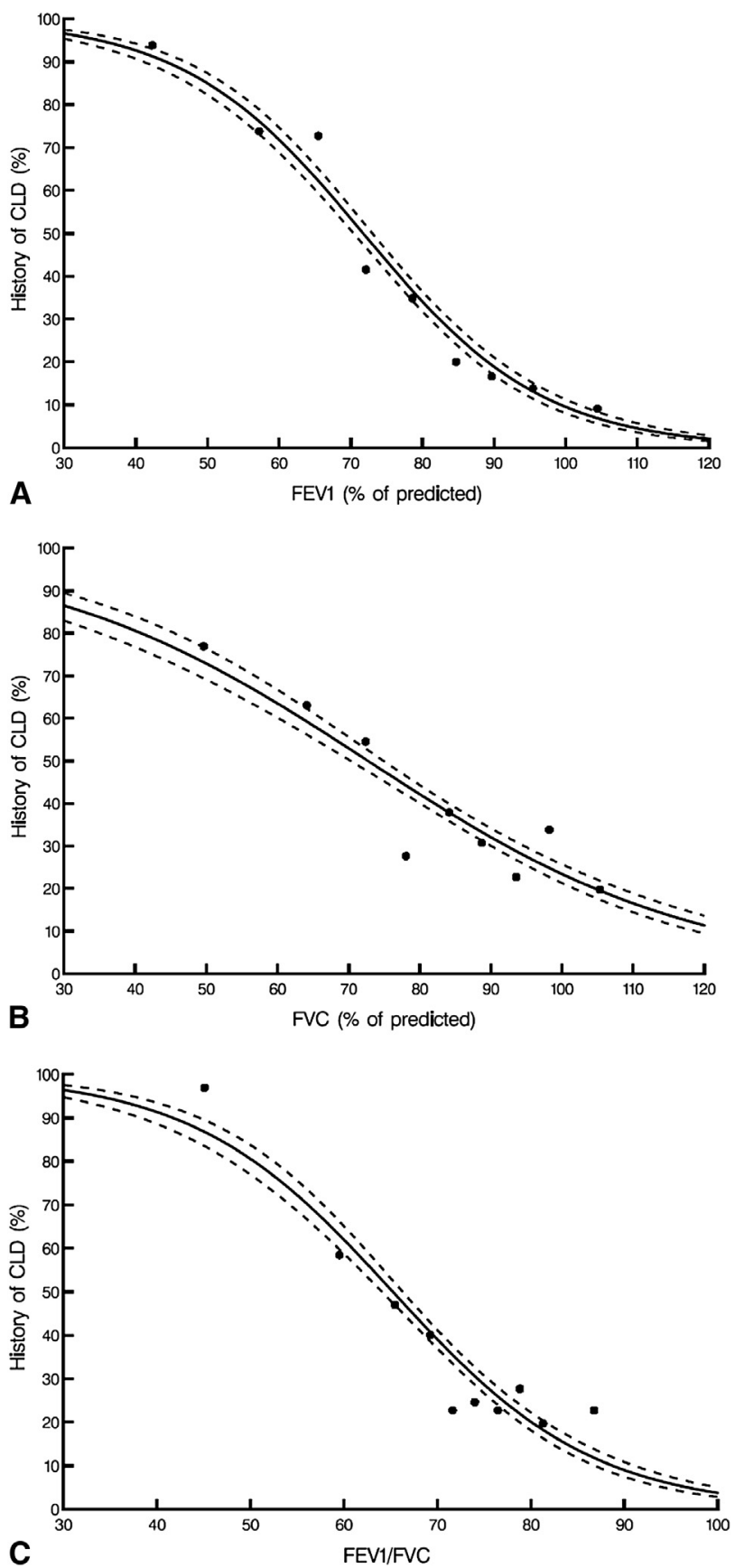

FIGURE E3. Relationship of clinical diagnosis of CLD to spirometry values. Closed circles represent percentages in grouped data, and solid line with its $68 \%$ confidence limits is a univariable logistic regression estimate of the trend. A, FEV1\%. B, FVC expressed as percent of predicted. C, FEV1/FVC. CLD, Chronic lung disease; FEV1, forced expiratory volume in 1 second; $F V C$, forced vital capacity. 


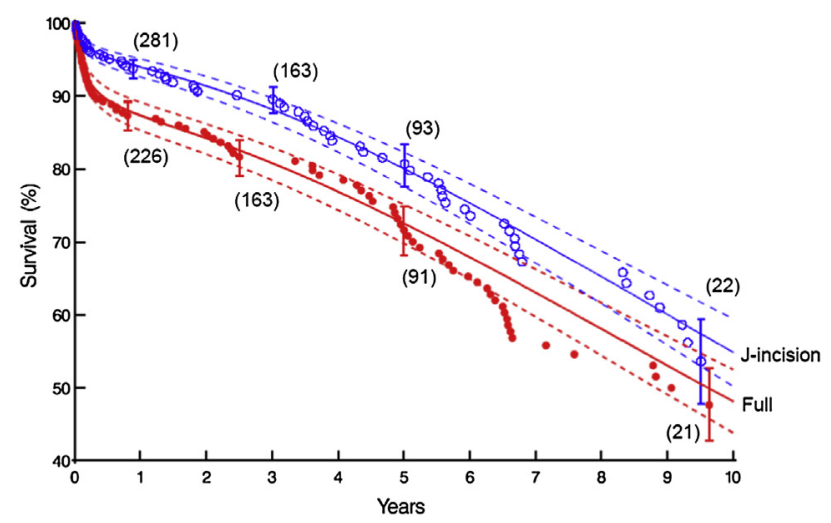

FIGURE E4. Unadjusted survival after aortic valve procedure stratified by approach. Each symbol represents a death positioned on a vertical axis by the Kaplan-Meier estimator, vertical bars are confidence limits equivalent to 1 standard error $(S E)$, and numbers in parentheses are patients still alive and traced at 1,3,5, and 10 years. Solid lines are parametric survival estimates enclosed within dashed $68 \%$ confidence bands equivalent to $\pm 1 \mathrm{SE}$.
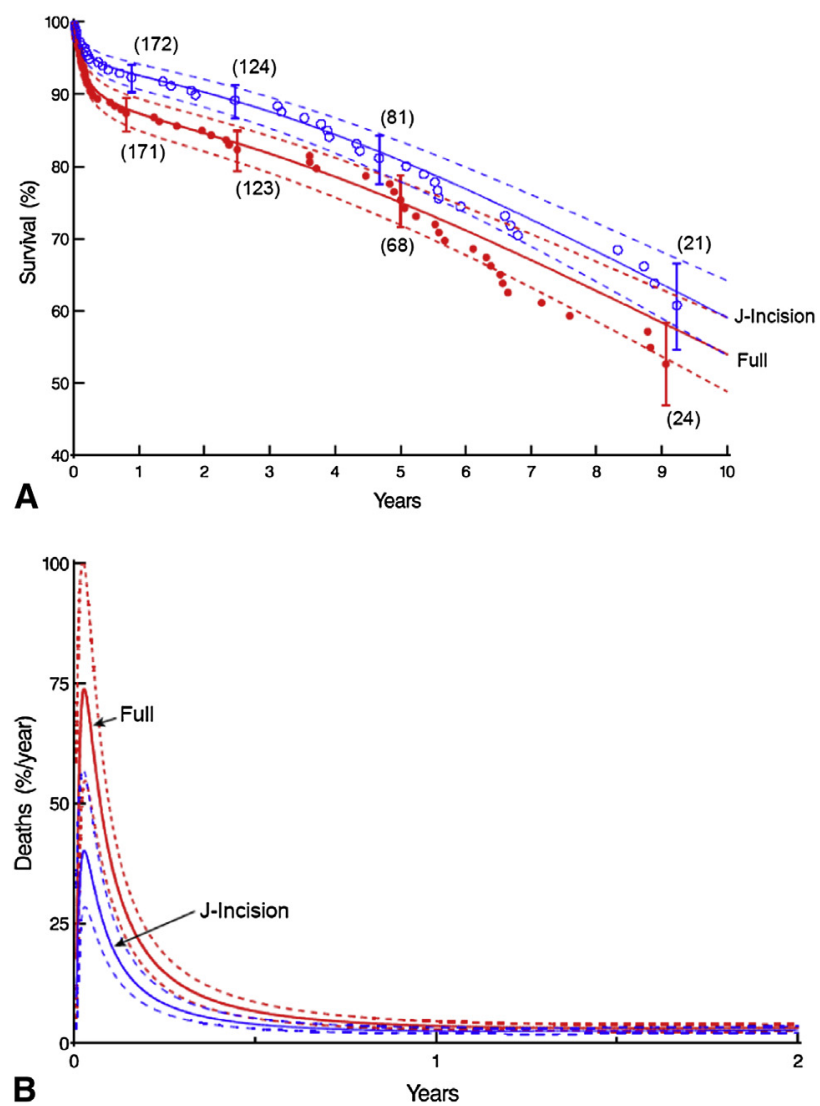

FIGURE E5. Mortality after AVR, stratified by approach (matched patient pairs). A, Survival. Each symbol represents a death positioned on a vertical axis by the Kaplan-Meier estimator, vertical bars are confidence limits equivalent to 1 standard error, and numbers in parentheses are patients still alive and traced at 1,3,5, and 10 years. Solid lines are parametric survival estimates enclosed within dashed $68 \%$ confidence bands equivalent to \pm 1 standard error. B, Hazard function. Parametric estimates (solid lines) are enclosed within dashed confidence bands equivalent to \pm 1 standard error. AVR, Aortic valve replacement. 
TABLE E1. Variables associated with surgical approach: Full sternotomy versus $\mathbf{J}$-incision

\begin{tabular}{|c|c|c|c|}
\hline Variable & Coefficient $\pm \mathrm{SE}$ & $\boldsymbol{P}$ & $\begin{array}{c}\text { Reliability } \\
(\%)^{*}\end{array}$ \\
\hline \multicolumn{4}{|l|}{ Factors favoring full sternotomy } \\
\hline \multicolumn{4}{|l|}{ Spirometry } \\
\hline Lower FEV1\%† & $-0.62 \pm 0.17$ & .0003 & 94 \\
\hline Higher FEV1/FVC $\ddagger$ & $1.6 \pm 0.33$ & $<.0001$ & 94 \\
\hline Greater left ventricular mass $\oint$ & $0.0056 \pm 0.0024$ & .02 & 83 \\
\hline Heart failure & $0.56 \pm 0.21$ & .008 & 88 \\
\hline Peripheral arterial disease & $0.77 \pm 0.32$ & .02 & 72 \\
\hline Higher bilirubin & $0.47 \pm 0.25$ & .06 & 52 \\
\hline \multicolumn{4}{|l|}{ Factor favoring J-incision } \\
\hline Higher EF\| & $0.67 \pm 0.27$ & .01 & 85 \\
\hline \multicolumn{4}{|c|}{$\begin{array}{l}\text { C-statistic of this parsimonious model is } 0.701 . S E \text {, Standard error; } F E V 1 \% \text {, forced } \\
\text { expiratory volume in } 1 \text { second, percent of predicted; } F E V 1 \text {, forced expiratory volume } \\
\text { in } 1 \text { second; } F V C \text {, forced vital capacity; } E F \text {, ejection fraction. *Percent of times factor } \\
\text { appeared in } 1000 \text { bootstrap models. } \dagger \operatorname{Exp}(\mathrm{FEV} 1 \% / 81) \text {, exponential transformation. } \\
\ddagger(\mathrm{FEV} 1 \% / \mathrm{FVC} / 72)^{2} \text {, squared transformation. } \S \text { Indexed by body surface area. } \\
\|(\mathrm{EF} / 52)^{-1} \text {, inverse transformation. }\end{array}$} \\
\hline
\end{tabular}

TABLE E2. Patient characteristics and operative details stratified by pulmonary function test (total $\mathbf{n}=\mathbf{2 6 1 9}$ )

\begin{tabular}{|c|c|c|c|c|c|}
\hline \multirow[b]{2}{*}{ Variable } & \multicolumn{2}{|c|}{ Pulmonary function test $(n=655)$} & \multicolumn{2}{|c|}{ No pulmonary function test $(n=1964)$} & \multirow[b]{2}{*}{$P$} \\
\hline & $\mathbf{n}^{*}$ & No. $(\%)$ or mean \pm SD & $\mathbf{n}^{*}$ & No. $(\%)$ or mean \pm SD & \\
\hline \multicolumn{6}{|l|}{ Demography } \\
\hline Women & 655 & $303(46)$ & 1964 & $758(39)$ & .0005 \\
\hline Age (y) & 655 & $68 \pm 13$ & 1964 & $64 \pm 14$ & $<.0001$ \\
\hline $\mathrm{BMI}\left(\mathrm{kg} \cdot \mathrm{m}^{-2}\right)$ & 610 & $30 \pm 7.6$ & 1699 & $29 \pm 6.8$ & .0002 \\
\hline NYHA functional class & 513 & & 1452 & & $<.0001$ \\
\hline I & & $90(18)$ & & $379(26)$ & \\
\hline II & & $259(50)$ & & $788(54)$ & \\
\hline III & & $147(29)$ & & $249(17)$ & \\
\hline IV & & $17(3.3)$ & & $36(2.5)$ & \\
\hline \multicolumn{6}{|l|}{ Indication for operation } \\
\hline Degenerative & 651 & $628(96)$ & 1953 & $1828(94)$ & .006 \\
\hline Other & 651 & $23(3.5)$ & 1953 & $125(6.4)$ & .006 \\
\hline \multicolumn{6}{|l|}{ Cardiac comorbidity } \\
\hline LVEF $(\%)$ & 639 & $55 \pm 11$ & 1834 & $55 \pm 10$ & .7 \\
\hline Aortic valve area $\left(\mathrm{cm}^{2}\right)$ & 552 & $0.71 \pm 0.27$ & 1486 & $0.71 \pm 0.25$ & .5 \\
\hline \multicolumn{6}{|l|}{ Aortic valve gradient $(\mathrm{mm} \mathrm{Hg})$} \\
\hline Mean & 579 & $47 \pm 16$ & 1588 & $50 \pm 18$ & .001 \\
\hline Peak & 579 & $81 \pm 26$ & 1593 & $84 \pm 28$ & .02 \\
\hline $\mathrm{LV}$ mass index $\left(\mathrm{g} \cdot \mathrm{m}^{-2}\right)$ & 567 & $126 \pm 41$ & 1547 & $134 \pm 47$ & $<.0001$ \\
\hline LA volume index $\left(\mathrm{mL} \cdot \mathrm{m}^{-2}\right)$ & 545 & $19 \pm 11$ & 1428 & $19 \pm 9.9$ & .5 \\
\hline Tricuspid regurgitation more than moderate & 614 & $17(2.8)$ & 1840 & $24(1.3)$ & .01 \\
\hline Atrial fibrillation/flutter & 603 & $24(4.0)$ & 1678 & $39(2.3)$ & .03 \\
\hline \multicolumn{6}{|l|}{ Noncardiac comorbidity } \\
\hline Hypertension & 655 & 455 (69) & 1964 & $1192(61)$ & $<.0001$ \\
\hline CLD & 655 & $250(38)$ & 1964 & $104(5.3)$ & $<.0001$ \\
\hline Past or current smoking & 653 & $421(64)$ & 1945 & $869(45)$ & $<.0001$ \\
\hline FEV1\% & 655 & $81 \pm 22$ & - & - & - \\
\hline FVC ( $\%$ of predicted $)$ & 655 & $86 \pm 20$ & - & - & - \\
\hline FEV1/FVC & 655 & $71 \pm 12$ & - & - & - \\
\hline
\end{tabular}

$S D$, Standard deviation; $B M I$, body mass index; $N Y H A$, New York Heart Association; $L V E F$, left ventricular ejection fraction; $L V$, left ventricle; $L A$, left atrial; $C L D$, chronic lung disease; $F E V 1 \%$, forced expiratory volume in 1 second, percent of predicted; $F E V I$, forced expiratory volume in 1 second; $F V C$, forced vital capacity. *Number of patients with data available. 
TABLE E3. Factors related to obtaining spirometry before aortic valve surgery ( $n=2619 ; 655$ patients with testing)

\begin{tabular}{|c|c|c|c|}
\hline $\begin{array}{c}\text { Variables associated with } \\
\text { preoperative spirometry testing }\end{array}$ & $\begin{array}{c}\text { Coefficient } \\
\pm \mathrm{SE} \\
\end{array}$ & $\boldsymbol{P}$ & $\begin{array}{c}\text { Reliability } \\
(\%)^{*}\end{array}$ \\
\hline Female & $0.33 \pm 0.11$ & .002 & 60 \\
\hline History of CLD & $2.37 \pm 0.14$ & $<.0001$ & 100 \\
\hline History of recent smoking & $0.77 \pm 0.11$ & $<.0001$ & 100 \\
\hline Preoperative atrial fibrillation & $0.78 \pm 0.31$ & .01 & 56 \\
\hline Higher triglycerides $\left(\mathrm{mg} \cdot \mathrm{dL}^{-1}\right)$ & $0.32 \pm 0.11$ & .003 & 52 \\
\hline $\begin{array}{l}\text { Lower preoperative } \mathrm{AV} \text { mean } \\
\text { gradient }(\mathrm{mm} \mathrm{Hg})\end{array}$ & $0.007 \pm 0.003$ & .04 & 67 \\
\hline Higher NYHA functional class & $0.28 \pm 0.08$ & .0006 & 84 \\
\hline More recent date of operation & $0.18 \pm 0.01$ & .02 & 100 \\
\hline
\end{tabular}

TABLE E4. Variables associated with higher preoperative forced expiratory volume in 1 second, percent of predicted

\begin{tabular}{lccc}
\hline \multicolumn{1}{c}{ Variable } & $\begin{array}{c}\text { Coefficient } \\
\pm \text { SE }\end{array}$ & $\boldsymbol{P}$ & $\begin{array}{c}\text { Reliability } \\
(\%)\end{array}$ \\
\hline Higher FEV1\% & & & \\
$\quad$ Male & $3.5 \pm 1.6$ & .03 & 60 \\
$\quad$ Older age & & & \\
$\quad$ Exp(age) & $-132 \pm 21$ & $<.0001$ & 100 \\
$\quad$ Age ${ }^{2}$ & $-3.2 \pm 1.2$ & .008 & 52 \\
Higher preoperative creatinine $\dagger$ & $0.12 \pm 0.05$ & .02 & 53 \\
Higher HDL & $4.6 \pm 2.3$ & .04 & 79 \\
Greater aortic valve area & $4.8 \pm 2.0$ & .02 & 57 \\
$\quad$ Higher LVEF $\ddagger$ & & & \\
Lower FEV1\% & $-24 \pm 1.4$ & $<.0001$ & 100 \\
$\quad$ History of CLD & $-3.7 \pm 1.5$ & .01 & 100 \\
History of smoking or recent & & & \\
$\quad$ smoker & $-4.7 \pm 1.8$ & .007 & 86 \\
$\quad$ History of heart failure & $-12 \pm 3.6$ & .001 & 86 \\
$\quad$ Preoperative atrial fibrillation & $-6.5 \pm 2.0$ & .002 & 64 \\
$\quad$ Lower preoperative BUN $\S$ &
\end{tabular}

Average $R^{2}$ of this model is 0.436 . SE, Standard error; $F E V 1 \%$, forced expiratory volume in 1 second, percent of predicted; $H D L$, high-density lipoprotein; $L V E F$, left ventricular ejection fraction; $C L D$, chronic lung disease; $B U N$, blood urea nitrogen. *Percent of times factor appeared in 1000 bootstrap models. $\dagger(1 / \text { creatinine })^{2}$, inverse squared transformation. $\ddagger(E F / 52)^{2}$, squared transformation. $\S \mathrm{Ln}(\mathrm{BUN})$, logarithmic transformation. 